\title{
Climatic niche shift and possible future spread of the invasive South African Orchid Disa bracteata in Australia and adjacent areas
}

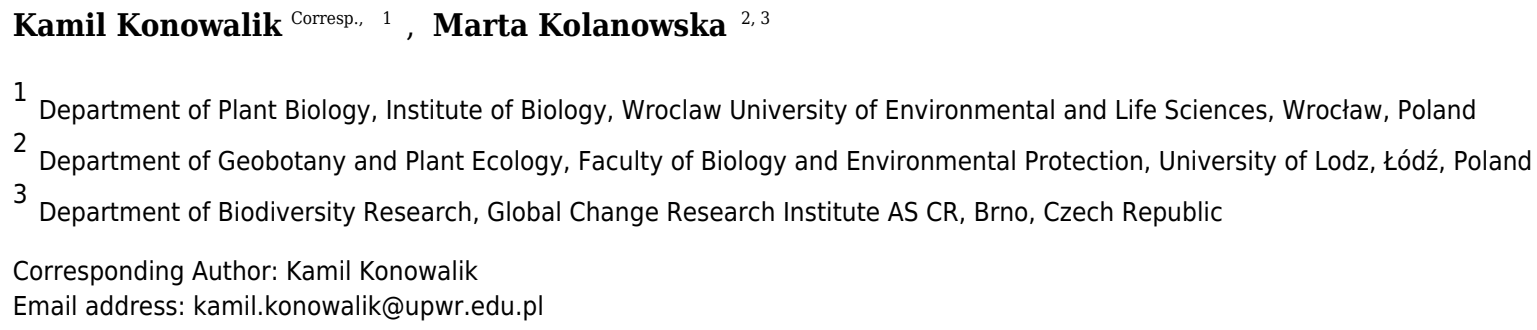

Orchids are generally regarded as plants with an insignificant invasive potential and so far only one species has proved to be harmful for native flora. However, previous studies on Epipactis helleborine and Arundina graminifolia indicate that the ecological aspects of range extension in their non-native geographical range are not the same for all species of orchids. Disa bracteata in its native range, South Africa, is categorized as of little concern in terms of conservation whereas in Australia it is naturalized and considered to be an environmental weed. The aim of this research was to determine the ecological preferences enabling the spread of Disa bracteata in Western and South Australia, Victoria and Tasmania and to evaluate the effect of future climate change on its potential range. The ecological niche modeling approach indicates that most of the accessible areas are already occupied by this species but future expansion will continue based on four climate change scenarios ( $r c p 26, r c p 45, r c p 60, r c p 85)$. Further expansion is predicted especially in eastern Australia and eastern Tasmania. Moreover, there are some unpopulated but suitable habitats in New Zealand, which according to climate change scenarios will become even more suitable in the future. The most striking result of this study is the significant difference between the environmental conditions recorded in the areas which $D$. bracteata naturally inhabits and invasive sites - that indicates a possible niche shift. In Australia the studied species continues to populate a new niche or exploit habitats that are only moderately represented in South Africa. 
1 Climatic niche shift and possible future spread of the invasive South African Orchid Disa

\section{2 bracteata in Australia and adjacent areas}

3

4 Kamil Konowalik ${ }^{1 *} \&$ Marta Kolanowska ${ }^{2,3}$

5

$6 \quad{ }^{1}$ Department of Plant Biology, Institute of Biology, Wroclaw University of Environmental and

7 Life Sciences, Kożuchowska 5b, 51-631 Wrocław, Poland

$8 \quad 2$ Department of Geobotany and Plant Ecology, Faculty of Biology and Environmental Protection,

9 University of Lodz, Banacha 12/16, 90-237 Lodz, Poland

$10{ }^{3}$ Department of Biodiversity Research, Global Change Research Institute AS CR, Bělidla 4a, 603

1100 Brno, Czech Republic

12

$13 *$ author for correspondence: e-mail: kamil.konowalik@upwr.edu.pl 


\section{Abstract}

16 Orchids are generally regarded as plants with an insignificant invasive potential and so far only

17 one species has proved to be harmful for native flora. However, previous studies on Epipactis

18 helleborine and Arundina graminifolia indicate that the ecological aspects of range extension in

19 their non-native geographical range are not the same for all species of orchids. Disa bracteata in

20 its native range, South Africa, is categorized as of little concern in terms of conservation whereas

21 in Australia it is naturalized and considered to be an environmental weed. The aim of this research

22 was to determine the ecological preferences enabling the spread of Disa bracteata in Western and

23 South Australia, Victoria and Tasmania and to evaluate the effect of future climate change on its

24 potential range. The ecological niche modeling approach indicates that most of the accessible areas

25 are already occupied by this species but future expansion will continue based on four climate

26 change scenarios (rcp26, rcp45, rcp60, rcp85). Further expansion is predicted especially in eastern

27 Australia and eastern Tasmania. Moreover, there are some unpopulated but suitable habitats in

28 New Zealand, which according to climate change scenarios will become even more suitable in the

29 future. The most striking result of this study is the significant difference between the environmental

30 conditions recorded in the areas which $D$. bracteata naturally inhabits and invasive sites - that

31 indicates a possible niche shift. In Australia the studied species continues to populate a new niche

32 or exploit habitats that are only moderately represented in South Africa.

\section{Introduction}

The study of biological invasions has been called "one of the hottest current topics in ecology" (Sol, 2001), mostly because together with habitat destruction and climate change the spread of non-native organisms is considered to be a major threat to biodiversity. In Australasia, 
38 invasive (= not native) species are a major problem, for example, the number of species of plants

39 reported as introduced, that have been released and may or may not have become naturalized in

40 Australia exceeds 28,000 (Randall, 2007). A subset of them have naturalized and are a threat to

41 the rich endemic flora of that continent (Coutts-Smith \& Downey, 2006; Randall, 2007; Duursma

42 et al., 2013) as the populations are self-sustaining and spreading without human assistance. In

43 addition, the eradication of invasive weeds is costly (Sinden et al., 2004). Governmental agencies

44 and private landowners invest large amounts of money in controlling the spread of weeds using

45 various methods to assess risk of their further spread. One of the emerging techniques is to evaluate

46 the potential future ranges of invasive species using climatic niche modeling (Peterson, 2003).

47 In this research we implemented modeling approach to evaluate the possible further spread

48 of invasive orchid species, Disa bracteata Sw., which was first reported in Australia relatively

49 recently, in 1944. This plant is listed in the Global Compendium of Weeds (GCW;

50 http://www.hear.org/gcw) and is the only weedy representative of the mainly sub-Saharan genus

51 Disa P.J. Disa bracteata is classified in the GCW as an environmental weed (species that invade

52 native ecosystems; Blood, 2001) or a naturalized species (self-sustaining and spreading

53 populations but not necessarily affecting the environment; Baker et al., 2005; Hussey et al., 1997).

54 D. bracteata is a South African endemic found in both the Eastern and Western Cape (Foden \&

55 Potter, 2005), where it is widespread and common, especially in areas subject to mild disturbance.

56 In undisturbed vegetation it is somewhat less frequent. D. bracteata is included on the Red List of

57 South African plants as a taxon of Least Concern (Raimondo et al., 2009; Foden \& Potter, 2005).

58 In the mid-20th-century it was brought to Australia where it became naturalized (Groves et al.,

59 2003). This orchid was first formally recorded near Bacchus Marsh, west of Melbourne, in 1944

60 (Wileman, 2015; Russell, 2015) and since 1945 additional reports came from areas of the Great 
61 Southern Region in Western Australia (vicinity of Albany). Later it was also recorded in South

62 Australia (in 1988) and Victoria (in 1994). Recently it was found in Tasmania (Viridans Biological

63 Databases). In Australia D. bracteata was probably accidentally introduced and it is now growing

64 along roadsides. Invasive populations are large with up to almost 80 mature individuals in one 65 square meter (Tucker, 2006; Trees For Life).

66 The aim of this research was to evaluate the similarities in the bioclimatic niches occupied

67 by invasive and native populations of $D$. bracteata and to estimate the potential further spread of 68 this species in Australia and adjacent areas. The comparison of the bioclimatic conditions 69 experienced by African and non-native plants was conducted to explain the nature of this invasion

70 by exploring the possible changes in the bioclimatic preferences of D. bracteata in early and 71 present stage of its spread in Australia. Currently it is unclear whether the studied species inhabits 72 similar climatic niches in Australia and Africa or whether it was able to colonise new niches in 73 Australia. The negative effect of the introduction of exotic orchid on the native flora was reported 74 only once so far (Recart, Ackerman \& Cuevas, 2013), but the actual impact of invasive 75 Orchidaceae on local plant communities remains poorly recognized. We do believe that results of 76 our analyses of possible future spread of $D$. bracteata will be valuable information that can be 77 used in planning conservation actions.

79 Materials and methods

80 Localities

81 A database of localities of D. bracteata was prepared based on the information recorded 82 on the labels of identified herbarium specimens deposited in MO, WAG, S, NY, AD, MEL, 83 CANB, HO, NSW, and PERTH. The herbaria acronyms follow Index Herbariorum (Thiers, 2018). 
84 The process of georeferencing follows Hijmans et al. (1999). The geographic coordinates provided

85 on the herbarium sheet labels were verified. If there was no geolocation data on the herbarium

86 sheet label, the description of the collection place recorded was assigned coordinates as precisely

87 as possible. In addition, the information provided by the South African National Biodiversity

88 Institute and Global Biodiversity Information Facility (GBIF) with a precision value of less than

$891000 \mathrm{~m}$ was used. A total of 187 native (1863-2013) and 747 invasive records (1945-2016) were

90 gathered (Supplementary file 1).

91

92 Niche modeling

93 The terminology used in this paper follows Peterson \& Soberón (2012). The distribution of the

94 studied orchid was evaluated by including in the analyses numerous parameters potentially

95 relevant to its occurrence. While the bioclimatic variables were commonly used as the only

96 predictor in previous studies on invasive plants (e.g. Mainali et al., 2015; Wang et al., 2017), in

97 our research we incorporated also vegetation, soil, and topographic factors. Due to the lack of data

98 on distribution of pollinators of $D$. bracteata and insufficient information on the mycorrhizal

99 associations of this species these two ecological aspects were omitted in the analyses.

100 Nineteen bioclimatic variables from the CHELSA version 1.1 database (Karger et al., 2016; Karger

101 et al., 2016) were used. The recent study by Bobrowski \& Schickhoff (2017) indicated that this

102 dataset performs better than other available climatic data in ecological niche modeling. Eighteen

103 soil characters relevant to plant growth were obtained from Global Soil Information Based on

104 Automated Mapping (Hengl et al., 2014; www.soilgrids.org) with a $250 \mathrm{~m}^{2}$ resolution and

105 upscaled to match the resolution and extent of the bioclimatic variables. Furthermore, several other

106 georeferenced factors were used in the analyses: potential vegetation (Ramankutty \& Foley, 1999), 
107 soil quality (Fischer et al., 2008) along with six topographic variables based on an altitude raster

108 (Supplementary file 2). Because some previous studies (Barve et al., 2011) indicated that usage of

109 a restricted area in ENM analysis is more reliable than calculating habitat suitability on the global

110 scale the region of our analysis was clipped using a rectangular mask enclosing known populations

111 and surrounding regions in order to estimate possible migration and/or spread. Since this species

112 continues to spread mainly in Australia, the northern border of the Australian continent was set as

113 the maximum extent of spread in this study. To account for co-linearity and select the most

114 important bioclimatic variables, the number of original bioclimatic data was reduced using the $\mathrm{R}$

115 package MaxentVariableSelection (Jueterbock, 2016). The following criteria were applied:

116 correlation threshold was set at 0.7 , contribution threshold at 1 and beta-multiplayer was tested in

117 the range of 1 to 15 using 0.5 steps and in the range of 1 to 1.5 using 0.1 steps. For each setting,

118 the model was run 10 times and the results were averaged to decrease the possibility of a random

119 selection even though all variables were treated a priori as equal. This algorithm evaluates

120 correlation and contribution mutually and is more objective than selection based on an expert

121 opinion and correlation which may be not repeatable and biased by the specific preferences of a

122 researcher.

123 The modeling was conducted using the maximum entropy method implemented in Maxent version

124 3.3.3k (Phillips, Dudík \& Schapire, 2004), which is commonly used in ecological studies and is

125 known to be reliable (Kolanowska \& Konowalik, 2014 and references therein). The maximum

126 number of iterations was set at $10^{4}$ and convergence threshold at $10^{-5}$. For each run, $20 \%$ of the

127 data was set aside and used as test points (Suárez-Seoane et al., 2008; Konowalik, Proćków \&

128 Procków, 2017; Walas et al., 2018). The "random seed" option, which provides a random test 
129 partition and background subset for each run was used. The run was performed as a bootstrap with

$13010^{3}$ replicates and the output was set to cumulative.

131 To evaluate the possible future expansion of D. bracteata within Australia, climate projections

132 obtained from Coupled Model Intercomparison Project Phase 5 (CMIPP5) were used. Four

133 "representative concentration pathways" (RCPs: rcp26, rcp45, rcp60, rcp85), which differ in

134 predicted $\mathrm{CO}_{2}$ concentration (Collins et al., 2013), were analyzed. We only considered the models

135 covering all four representative concentration pathways for the year 2070 (average for 2061-2080).

136 These models were obtained from www.worldclim.org (Supplementary file 2). To reduce the bias

137 caused by the selection of only one specific model, they were averaged and the ensemble map for

138 each variable, in particular RCP, was computed (Konowalik, Proćków \& Proćków, 2017). This

139 step simplifies the interpretation as it shows the general trend specific for a given RCP scenario

140 while reducing extremes and uncertainties of particular models. Since many soil variables may be

141 potentially affected by climate warming and due to the absence of such models for the region

142 studied they were not used for future predictions. For the presentation of results, output grids with

143 a cumulative scale were converted to binary grids using maximum training sensitivity plus a

144 specificity threshold (Liu et al., 2005; Liu, Newell \& White, 2016).

145 A range of methods described in previous studies (Kolanowska \& Konowalik, 2014) were used to

146 analyse output from niche modeling and quantify differences between indigenous and invasive

147 populations. To measure the degree of similarity between occupied niches of both groups the niche

148 equivalency test (Warren, Glor \& Turelli, 2008) was calculated using 'ENMTools' R package

149 (Warren, 2016). Niche overlaps (D and I) were calculated using methods of Warren, Glor \& Turelli

150 (2008) and Broennimann et al. (2012). Schoener's D statistic uses direct measures of species

151 density, which in this study were changed to measures of densities of occurrence modelled in 
152 environmental space. 'I' statistic was based on the modified Hellinger distance that compares two

153 probability distributions. These two metrics range from 0 (no similarity) to 1 (high similarity). The

154 bias metric (Pressey et al., 2000) was calculated as described previously (Kolanowska \&

155 Konowalik, 2014). It shows differences in ecological tolerance between invasive and native

156 populations and the value of this metric can be either positive (when novel conditions with higher

157 values are experienced by invasive populations) or negative (if conditions recorded in indigenous

158 populations have higher median than those in newly occupied areas). To visualize interdependence

159 of different populations in the simplified (two dimensional) space Principal Component Analysis

160 (PCA) was performed on all available variables (Appendix 3), as described in Kolanowska \&

161 Konowalik (2014) using R (R Core Team, 2016). All GIS operations were done in open source

162 software QGis (Quantum GIS Development Team, 2016) and R (R Core Team, 2016) using

163 packages 'raster' (Hijmans, 2016) and 'rgdal' (Bivand, Keitt \& Rowlingson, 2016).

\section{Results}

166 Variable selection and model evaluation

167 According to MaxentVariableSelection (Jueterbock, 2016), the lowest AIC, AICc, BIC scores and 168 highest AUC for training dataset are assigned to the model with beta-multiplayer $=1$. The final set

169 of the most important and uncorrelated variables included eight of the original 49 variables:

170 Temperature Annual Range (Bio7), Mean Temperature in Wettest Quarter (Bio8), Precipitation

171 Seasonality (Bio15), Precipitation in Warmest Quarter (Bio18), Precipitation in Coldest Quarter

172 (Bio19), Sand Content, Soil Organic Carbon Content, Soil pH.

173 The calculated value of the area under the curve (AUC) was 0.98 (SD 0.001), which indicates

174 excellent model performance. Additional summary statistics included the mean cross-entropy 
175 (mxe), which equaled 0.019 (SD 0.001) and root-mean-squared error (RMSE), which was 0.073

176 (SD 0.002). Both of these values were very low, which also indicate a high reliability of created

177 models.

178 Potential distribution of suitable niches under current climatic conditions

179 The model of the current distribution of suitable bioclimatic niches for D. bracteata was calculated

180 based on all uncorrelated variables and a model in which only climatic factors were considered

181 exclusively were visually congruent (Fig. 1 A and B, Fig. 2 A and B). The main difference

182 concerns the transitional zone between the western and eastern Cape in Africa and the Nullarbor

183 Plain in Australia. The first region was not indicated as suitable in the model based on climatic

184 factors, whereas the second one was shown as suitable for this orchid in this analysis. Otherwise

185 the difference may be seen in the scale of suitable habitat - while the general trend is very similar,

186 both models differ slightly in the extent of the predicted suitable niche. Currently, the species is

187 found in most of the suitable habitats in both Africa and Australia. Yet there are some areas in

188 Australia that are not colonized - the Eyre Peninsula and some smaller areas detached from the

189 main distribution. A vast area of Tasmania was predicted to be suitable but so far the occurrence

190 of $D$. bracteata has been reported only from the northern part of the island. Also, there were no

191 records of this orchid from New Zealand (especially the North and South Islands) although the

192 models indicate the existence of suitable habitat in this area.

193 Future changes in the extent of suitable habitat

194 Future climate scenarios indicate that the extent of the suitable bioclimatic niches in South Africa

195 will be very similar to the one observed today. Nevertheless, depending on the climate change

196 scenario used the extent of native geographical range of the study orchid can slightly decrease or

197 increase. Two models (rcp26 and rcp60) predict that suitable niches for D. bracteata will become 
198 available along the Atlantic coast, near the border of Namibia and South Africa, in areas around

199 northern Namaqualand, Sperrgebiet and Lüderitz Bay (Figure 1: C and E).

200 Within the invasive range, all models indicate that additional suitable niches could occur in New

201 Zealand, especially along the southern coast of North Island and the South-eastern coast of South

202 Island. Simultaneously, all scenarios predict range contraction in Western Australia, especially in

203 the area north of Leeuwin-Naturaliste Ridge.

204 Apart from these general trends, each of the future climate scenarios gave specific information on

205 the future potential range of D. bracteata. The rcp26 scenario prediction is that more suitable sites

206 will be located in the south-western and south-eastern part of the Great Dividing Range, south-

207 central and south-eastern part of the Nullarbor Plain, and in the northern part of New South Wales

208 (Fig. 2C). Scenario rcp45 indicates a potential expansion of range in south-western and south-

209 eastern part of the Great Dividing Range and south-western part of the Nullarbor Plain (Fig. 2D).

210 Scenario rcp60, like the rcp26 scenario, predicts the occurrence of more suitable bioclimate in the

211 south-western and south-eastern part of the Great Dividing Range, south-central and south-western

212 part of Nullarbor Plain and in the northern part of New South Wales (Fig. 2E). Rcp85 scenario

213 indicates that $D$. bracteata may spread in the south-western part of the Great Dividing Range and

214 south-central and south-eastern part of Nullarbor Plain (Fig. 2F).

215 Niche overlap and identity

216 The overlap between the studied environmental requirements of invasive and the natural

217 populations is moderate or even low. Statistics calculated according to Broennimann et al. (2012)

218 were $\mathrm{D}=0.35$ and $\mathrm{I}=0.58$. These values were slightly higher using the method developed by

219 Warren, Glor \& Turelli (2008): $\mathrm{D}=0.44$, and $\mathrm{I}=0.73$. Also, niche identity tests reveal that the

220 bioclimatic niches occupied by invasive and natural populations were different $(\mathrm{p}<0.01)$. Yet 
221 visualization using PCA (Figure 3) indicates a large overlap between the niches with only a small

222 proportion of which is different.

223 Analyzed environmental conditions recorded at the sites occupied by this species are illustrated in

224 Figure 4. To measure the dissimilarity between invasive and native populations a bias metric was

225 calculated. It indicates that all invasive populations occupy relatively different habitats compared

226 to populations in Africa (Chi-squared $\left.=46.031, \mathrm{p}=4.9 \times 10^{-4}\right)$. The same result is obtained when

227 the invasive records are considered as one dataset or when the records are divided into those for

228 Eastern and Western Australia (Chi-squared $\left.=73.807, \mathrm{p}=4.9 \times 10^{-4}\right)$. Nevertheless, the suitable

229 niches of both groups of Australian populations are also different (Table 1). There are, however,

230 two similarities in the site characteristics of these two Australian regions: there is a greater sand

231 content and lower precipitation in the warmest quarter in the areas occupied relative to that in areas

232 occupied by natural populations. Others have either a medium difference (e.g. soil pH) or a

233 significant dissimilarity (e.g. temperature annual range, mean temperature in wettest quarter,

234 precipitation seasonality, precipitation in coldest quarter and soil organic carbon content; Table 1).

236 Discussion

237 Orchids are not usually regarded as weeds although some, e.g. Epipactis atrorubens, E. helleborine 238 and Dactylorhiza majalis, colonize secondary habitats in temperate Europe (Adamowski, 2006;

239 Rewicz, Kołodziejek \& Jakubska-Busse, 2015). Even fewer species are reported as invasive (e.g.

240 Ackerman, 2007) and so far only one, Spathoglottis plicata, has been shown to negatively affect

241 native plants (Recart, Ackerman \& Cuevas, 2013).

242 The invasive success of D. bracteata has not been thoroughly investigated and the mechanisms of 243 this phenomenon remain unclear. The only predictive models are in Weed Futures 
244 (www.weedfutures.net; Duursma et al., 2013). Most ground orchids usually do not have great

245 potential for spreading because of their very specific ecological requirements. Orchidaceae often

246 have specific insect pollinators and specific mycorrhizal associations that need to be present in the

247 soil to enable seed germination (e.g. Batty et al., 2002; Cozzolino \& Widmer, 2005, McCormick

248 \& Jacquemyn, 2014). Many species of orchids will only germinate with the aid of one or a few

249 species of fungus so their distribution, and hence ecological success, is heavily dependent on

250 suitable conditions for the fungus. Disa bracteata appears to be able to form an association with a

251 large number of fungal partners, especially those that can survive in disturbed soils (Bonnardeaux

252 et al., 2007), thus it is much less limited in terms of the places and conditions in which it may

253 become established. For this reason, we did not incorporate the distribution of mycorrhizal fungi

254 in our analyses. It is noteworthy that the incorporation of a fungal factor in any analysis of orchid

255 distribution is extremely difficult. Most orchid mycorrhizal fungi belong to the genus Rhizoctonia,

256 a diverse polyphyletic group that is difficult to classify and molecular methods have become the

257 standard means of assigning these orchid fungi to groups within the Rhizoctonia alliance

258 (Bonnardeaux et al., 2007). Because of the lack of data on the distribution of specific fungi it is

259 not possible to use such data in ecological niche modeling.

260 As seed production in Disa bracteata is pollinator-independent there was no need to incorporate

261 the potential distribution of any pollinator in order to get a more realistic potential distribution of

262 this orchid. Disa bracteata appears to be self-pollinating as a result of the breakup of pollinia in

263 the anther (Kurzweil \& Johnson, 1993). Generally, this is not beneficial for genetic variability,

264 however it does enable it to produce a large number of seeds. High propagule pressure greatly

265 enhances the chances of the establishment of invasive species (Colautti, Grigorovich \& MacIsaac,

266 2006). In fact, genetic variability seems to be less important as many successful invaders reproduce 
267 vegetatively. This is frequently the only mode of reproduction in some invasive species. This is

268 often influenced by environmental conditions that are not suitable for the full development of a

269 plant e.g. maturation of seeds. Ideally, even in such cases an invasive species may couple

270 vegetative propagation with occasional sexual reproduction in order to respond to a suite of

271 selective pressures and propagate efficiently (Atwater et al., 2017).

272 The environmental similarity between Australia and South Africa enabled numerous African

273 plants to naturalize in Australia. 15\% of naturalized flora of South Australia consists of species

274 native to South Africa (Kloot, 1986; Scott \& Panetta, 1993). Slightly higher contribution of African

275 plants was observed in Western Australia (17\%; Scott \& Delfosse, 1992; Scott \& Panetta, 1993).

276 It is worth to notice that the two species considered as major environmental weeds in Australia

277 and New Zealand, Chrysanthemoides monilifera (Asteraceae) and Asparagus asparagoides

278 (Asparagaceae), are of African origin (Thorp \& Lynch, 2000).

279 Invasive species often experience release from biotic interactions and dispersal barriers in their 280 non-native ranges (Torchin et al., 2003; Colautti et al., 2004; Jiménez-Valverde \& Peterson, 2011).

281 While the visualization using PCA indicate a large overlap between the niches of African and

282 invasive populations of $D$. bracteata they are not the same and that small difference is important

283 as it influences the results of the niche identity test.

284 Another interesting result is that the niche of invasive populations has changed over time as the

285 colonization process has progressed. At the time of the first introduction, which was around 1944

286 (date of the first recorded specimen), only a few localities were known and the conditions there

287 were similar to those in its natural range. However, over time more populations were established,

288 which eventually gave rise to the colonization of the eastern part of Australia. The first

289 georeferenced specimen collected in 1989 was found on the southern Adelaide Plains. Dispersal 
290 to the western part of the continent involved colonizing novel habitats or those that are not

291 available to Disa in its native range (Supplementary file 3). This shift is congruent with the

292 Köppen-Geiger climate classification system (Peel et al., 2007), which indicates that the difference

293 in niches may be influenced by the climate availability or different preferences within both ranges.

294 In Africa, six climatic types were occupied while in Australia two of them were not populated and

295 the majority of established populations occurred within the Csb climate (Coastal Mediterranean).

296 The pattern of shifting niche of invasive species was detected in some previous studies in cases

297 when available evidence suggests use of novel environments by alien species in the invaded range

298 (Medley, 2010; Petersen 2012; Di Febbraro et al., 2013) when those conditions could be

299 unavailable or inaccessible in the native range (Broennimann \& Guisan, 2008; Godsoe, 2010;

300 Guisan et al., 2014; Qiao, Escobar \& Peterson 2017). Additionally, there was a difference between

301 Eastern and Western Australia: in the former second most frequent climate type is the $\mathrm{Cfb}$ (Marine

302 With Mild Winter), while in the latter this position belongs to the Csa climate (Interior

303 Mediterranean; Figure 5). Thus it is not an entirely new climate but rather a shift of the climatic

304 preferences that may be attributed to the establishment of invasive populations in areas possessing

305 different composition of available climates. However, it may be related to novel preferences as

306 well since all climates that are present in Africa are present in Australia. Interestingly, areas of

307 some types of climate are less frequent in Africa and apparently are sparsely populated by $D$.

308 bracteata but mainly by other Disa s.l. species. This may indicate that in its native distribution

309 there are factors that prevent $D$. bracteata occupying this niche, such as biotic interactions

310 (possibly with other closely related species) while in Australia this constraint is absent and $D$.

311 bracteata is able to colonize these new sites. Studies on niche shifting species indicate this occurs

312 in various areas (Broennimann et al., 2007; Elith, Kearney \& Phillips, 2010) but it is relevant to 
313 fewer than $15 \%$ of plant invaders (Petitpierre et al., 2012). There are significant differences

314 between the climatic niches occupied by invasive and native populations of another invasive

315 species of orchid, E. helleborine (Kolanowska 2013), but in this case, no shift within the Köppen-

316 Geiger climate was found. A study of the niche shifts of plants introduced into Australia found

317 that none of 26 species included in this study changed their Köppen-Geiger climatic niche

318 (Gallagher et al., 2010).

319 In the case of $D$. bracteata a significant difference in the proportion among climates in areas 320 occupied in Africa and Australia was recorded (Fisher's Exact Test $p=1.5 \times 10^{-5}$ ). The same result

321 is obtained when Africa is compared with two regions of Australia considered separately (Africa

322 vs. Eastern Australia: Fisher's Exact Test $\mathrm{p}=1.4 \times 10^{-4}$, Africa vs. Western Australia: Fisher's

323 Exact Test $\mathrm{p}=1.3 \times 10^{-3}$ ). This suggests that irrespective of invaded region, D. bracteata occurs

324 in Australia in habitats characterized by different climatic conditions (in terms of climatic zones)

325 than these recorded in Africa. Even though both contain the same climatic types they differ in their

326 abundance and relative areas. This may be influenced by the total available land area which is

327 much smaller in Southern Africa that is stretched along meridians while Australia is rather

328 stretched along parallels.

329 Disa bracteata may be the first record of such a shift within Australia. When estimating niche

330 conservatism and changes in future range one needs to bear in mind that correct estimation of the

331 latter is tricky because acquiring a new niche is an active process possibly linked to novel

332 adaptations that may not be known at the time of a study (Thuiller et al., 2008; Elith, Kearney \&

333 Phillips, 2010). Alexander \& Edwards (2010) suggested that the probability of a niche shift in

334 invasive species depends primarily upon the ecological and genetic processes limiting the species

335 in its native range. Unfortunately, during our studies we did not have access to a sufficient amount 
336 of molecular data to explore genetic differences between African and invasive populations of $D$.

337 bracteata.

338

339 Conclusions

340 A South African D. bracteata has become invasive in Australia and it is already present on a large

341 part of the continent. Created models suggest that area with the suitable niche for this species is

342 larger than that currently occupied by the studied orchid thus the spread of this species will

343 continue. How this expansion will proceed depends on future changes in the factors influencing

344 its distribution and primarily on the magnitude of the climate modification. As demonstrated here

345 it is very likely that a niche shift has occurred in this case so the further spread of studied orchid

346 should be monitored. Altogether, the results of this study indicate the need of further research on

347 the spread of $D$. bracteata, especially analyses of genetic differences between native and invasive 348 populations.

\section{Acknowledgements}

351 We would like to thank Anthony Dixon for language correction of our manuscript. Nigel Swarts 352 and other anonymous reviewers are thanked for their suggestions improving this manuscript.

354 References

355 Ackerman J. 2007. Invasive Orchids: Weeds we hate to love? Lankesteriana 7(1-2): 19-21.

356 Adamowski W. 2006. Expansion of native orchids in anthropogenous habitats. Polish Botanical 357 Studies 22: 35-44. 
358 Alexander JM, Edwards PJ. 2010. Limits to the niche and range margins of alien species. Oikos 359 119(9): 1377-1386.

360 Atwater DZ, Kim W, Tekiela DR, Barney JN. 2017. Competition and propagule density affect 361 sexual and clonal propagation of a weed. Invasive Plant Science and Management 10(1): $17-25$.

363 Barve N, Barve V, Jimenez-Valverde A, Lira-Noriega A, Maher SP, Peterson AT, Soberóna J, 364 Villalobos F. 2011. The crucial role of the accessible area in ecological niche modeling and species distribution modeling. Ecological Modelling 222: 1810-1819.

366

367

368

369

370

371

372

373

374

375

376

377

378

379

Batty AL, Dixon KW, Brundrett MC, Sivasithamparam K. 2002. Orchid conservation and mycorrhizal associations. In: Sivasithamparam K, Dixon KW,Barrett RL, eds. Microorganisms in Plant Conservation and Biodiversity. Dordrecht: Kluwer Academic Publishers, 195-226.

Bivand R, Keitt T, Rowlingson R. 2016. rgdal: Bindings for the Geospatial Data Abstraction Library. R package version 1.2-5. https://CRAN.R-project.org/package=rgdal

Blood K. 2001. Environmental weeds: A field guide for SE Australia. Mt Waverley: C.H. Jerram \& Associates.

Bonnardeaux Y, Brundrett M, Batty A, Dixon K, Koch J, Sivasithamparam K. 2007. Diversity of mycorrhizal fungi of terrestrial orchids: compatibility webs, brief encounters, lasting relationships and alien invasions. Mycological Research 111(Pt 1): 51-61.

Bobrowski M, Schickhoff U. 2017. Why input matters: Selection of climate data sets for modeling the potential distribution of a treeline species in the Himalayan region. Ecological Modeling 359: 92-102. 
380 Broennimann O, Treier UA, Müller-Schärer H, Thuiller W, Peterson AT, Guisan A. 2007.

381 Evidence of climatic niche shift during biological invasion. Ecology Letters 10(8): 701382709.

383 Broennimann O, Guisan A. 2008. Predicting current and future biological invasions: Both native 384 and invaded ranges matter. Biology Letters 4: 585-589.

385 Broennimann O, Fitzpatrick MC, Pearman PB, Petitpierre B, Pellissier L, Yoccoz NG, Thuiller 386 W, Fortin MJ, Randin C, Zimmermann NE, Graham CH, Guisan A. 2012. Measuring ecological niche overlap from occurrence and spatial environmental data. Global Ecology and Biogeography 21: 481-497.

Di Febbraro M, Lurz PWW, Genovesi P, Maiorano L, Girardello M, Bertolino S. 2013. The use of climatic niches in screening procedures for introduced species to evaluate risk of spread: A case with the American Eastern Grey Squirrel. PLoS ONE 8: e66559.

Liu C, Berry P, Dawson T, Pearson R. 2005. Selecting thresholds of occurrence in the prediction 393 of species distributions. Ecography 28(3): 385-393.

394 Liu C, Newell G, White M. 2016. On the selection of thresholds for predicting species occurrence with presence-only data. Ecology and Evolution 6(1): 337-348.

396 Colautti RI, Ricciardi A, Grigorovich IA, MacIsaac HJ. 2004. Is invasion success explained by the enemy release hypothesis? Ecology Letters 7(8): 721-733.

398 Colautti R, Grigorovich I, MacIsaac H. 2006. Propagule pressure: A null model for biological invasions. Biological Invasions 8(5): 1023-1037.

400 Collins M, R. Knutti R, J. ArblasterJ, J.-L. Dufresne J-L, T. Fichefet T, P. Friedlingstein P, X. Gao X, W.J. Gutowski WJ, T. Johns T, G. Krinner G, M. Shongwe M, C. Tebaldi C, A.J. Weaver AJ, M. Wehner M. 2013. Long-term Climate Change: Projections, Commitments 
403

404

405

406

407

408

409

410

411

412

413

414

415

416

417

418

419

420

421

422

423

and Irreversibility. In: Stocker TF, Qin D, Plattner G-K, Tignor M, Allen SK, Boschung J, Nauels A, Xia Y, Bex V, Midgley PM, eds. Climate Change 2013: The Physical Science Basis. Contribution of Working Group I to the Fifth Assessment Report of the Intergovernmental Panel on Climate Change. Cambridge and New York: Cambridge University Press, 1029-1136.

Coutts-Smith AJ, Downey PO. 2006. The impact of weeds on threatened biodiversity in New South Wales. Technical Series no. 11. Adelaide: CRC for Australian Weed Management.

Cozzolino S, Widmer A. 2005. Orchid diversity: an evolutionary consequence of deception? Trends in Ecology \& Evolution 20: 487-494.

Duursma DE, Gallagher RV, Roger E, Hughes L, Downey PO, Leishman MR. 2013. NextGeneration invaders? hotspots for naturalised sleeper weeds in australia under future climates. PLOS ONE 8(12): e84222.

Elith J, Kearney M, Phillips S. 2010. The art of modeling range-shifting species. Methods in Ecology and Evolution 1(4): 330-342.

Elith J, Phillips SJ, Hastie T, Dudík M, Chee YE, Yates CJ. 2011. A statistical explanation of MaxEnt for ecologists. Diversity and Distributions 17: 43-57.

Fischer G, Nachtergaele F, Prieler S, van Velthuizen HT, Verelst L, Wiberg, 2008. Global Agroecological Zones Assessment for Agriculture (GAEZ 2008). Laxenburg, Austria and FAO, Rome, Italy: IIASA.

Foden W, Potter L. 2005. Disa bracteata Sw. National Assessment: Red List of South African Plants version 2015.1. Accessed on 2015/11/15 
424 Gallagher RV, Beaumont LJ, Hughes L, Leishman MR. 2010. Evidence for climatic niche and 425 biome shifts between native and novel ranges in plant species introduced to Australia. $426 \quad$ Journal of Ecology 98(4): 790-799.

427 Godsoe W. 2010. Regional variation exaggerates ecological divergence in niche models. $428 \quad$ Systematic Biology 59: 298-306.

429 Groves RH, Hosking JR, Batianoff GN, Cooke DA, Cowie ID, Johnson RW, Keighery GJ, Lepschi 430 BJ, Mitchell AA, Moerkerk M, Randall RP, Rozefelds AC, Walsh NG, Waterhouse BM. 2003. Weed categories for natural and agricultural ecosystem management. Canberra:

Guisan A, Petitpierre B, Broennimann O, Daehler C, Kueffer C. 2014. Unifying niche shift studies: Insights from biological invasions. Trends in Ecology \& Evolution 29: 260-269.

Hengl T, de Jesus JM, MacMillan RA, Batjes NH, Heuvelink GB, Ribeiro E, Samuel-Rosa A, Kempen B, Leenaars JGB, Walsh MG, Gonzalez MR. 2014. SoilGrids1km — global soil information based on automated mapping. PLOS ONE 9(8): e105992.

Hijmans RJ. 2016. raster: Geographic Data Analysis and Modeling. R package version 2.5-8. Available at https://CRAN.R-project.org/package=raster

Hijmans RJ, Cameron SE, Parra JL, Jones PG, Jarvis A. 2005 Very high resolution interpolated climate surfaces for global land areas. International Journal of Climatology25: 1965-1978.

Hijmans RJ, Schreuder M, De La Cruz J, Guarino L. 1999. Using GIS to check co-ordinates of genebank accessions. Genetic Resources and Crop Evolution 46: 291-296.

444 Hussey BMJ, Keighery GJ, Cousens RD, Dodd J, Lloyd SG. 1997. Western Weeds, a guide to the 445 weeds of Western Australia. Australia: Plant Protection Society of Western Australia. 
446 Jiménez-Valverde A, Peterson A. 2011. Use of niche models in invasive species risk assessments. 447 Biological Invasions 13(12): 2785-2797.

448 Jueterbock A, Smolina I, Coyer JA, Hoarau G. 2016. The fate of the Arctic seaweed Fucus 449 distichus under climate change: an ecological niche modeling approach. Ecology and $450 \quad$ Evolution 6(6): 1712-1724.

451 Karger DN, Conrad O, Böhner J, Kawohl T, Kreft H, Soria-Auza RW, Zimmermann NE, Linder HP, Kessler M. 2016. Climatologies at high resolution for the Earth land surface areas. arXiv:1607.00217 [physics].

454 Karger DN, Conrad O, Böhner J, Kawohl T, Kreft H, Soria-Auza RW, Zimmermann NE, Linder 455 456 HP, Kessler M. 2016. CHELSA climatologies at high resolution for the earth's land surface areas (Version 1.1). World Data Center for Climate.

Kloot PM. 1986. Checklist of the introduced species naturalised in South Australia. Department of Agriculture South Australia Technical Paper 14: 1-111.

Kolanowska M. 2013. Niche Conservatism and the Future Potential Range of Epipactis 461 helleborine (Orchidaceae). PLoS ONE 8(10): e77352. doi: 10.1371/journal.pone.0077352

Kolanowska M, Konowalik K. 2014. Niche conservatism and future changes in the potential area 463 coverage of Arundina graminifolia, an invasive orchid species from southeast Asia. Biotropica 46(2): 157-165.

Konowalik K, Proćków M, Proćków J. 2017. Climatic niche of Selinum alatum (Apiaceae, Selineae), a new invasive plant species in Central Europe and its alterations according to the climate change scenarios: Are the European mountains threatened by invasion? PLOS ONE 12(8): e0182793. 
469 Kuemmerle T, Hickler T, Olofsson J, Schurgers G, Radeloff VC. 2012. Reconstructing range 470 dynamics and range fragmentation of European bison for the last 8000 years. Diversity and 471 Distributions 18: 47-59.

472 Kurzweil H, Johnson SD. 1993. Auto-pollination in Monadenia bracteata. South African Orchid 473 Journal 24: 21-22.

474

475

476

477

478

479

480

481

482

483

484

485

486

487

488

489

490

491
BB, Parmesan C. 2015. Projecting future expansion of invasive species: comparing and improving methodologies for species distribution modeling. Global Change Biology 21(12): 4464-4480.

Mason SJ, Graham NE.2002. Areas beneath the relative operating characteristics (ROC) and relative operating levels (ROL) curves: Statistical significance and interpretation. Quarterly Journal of the Royal Meteorological Society 128: 2145-2166

McCormick MK, Jacquemyn H. 2014. What constrains the distribution of orchid populations? New Phytologist 202: 392-400.

Medley KA. 2010. Niche shifts during the global invasion of the Asian tiger mosquito, Aedes albopictus Skuse (Culicidae), revealed by reciprocal distribution models. Global Ecology and Biogeography 19: 122-133.

Qiao H, Escobar LE, Peterson AT. 2017. Accessible areas in ecological niche comparisons of invasive species: Recognized but still overlooked. Scientific Reports 7: 1213.

Peel MC, Finlayson BL, McMahon TA. 2007. Updated world map of the Köppen-Geiger climate classification. Hydrology and Earth System Sciences 11: 1633-1644.

Petersen MJ. 2012. Evidence of a climatic niche shift following North American introductions of two crane flies (Diptera; genus Tipula). Biological Invasions 15: 885-897. 
492 Peterson AT. 2003. Predicting the geography of species' invasions via ecological niche modeling. 493 The Quarterly Review of Biology 78(4): 419-433.

494 Peterson AT, Soberón J. 2012. Species Distribution Modeling and Ecological Niche Modeling: 495 Getting the Concepts Right. Natureza \& Conservação 10(2):102-107.

496 Petitpierre B, Kueffer C, Broennimann O, Randin C, Daehler C, Guisan A. 2012. Climatic niche shifts are rare among terrestrial plant invaders. Science 335(6074): 1344-1348.

Phillips SJ, Dudík M, Schapire RE. 2004. A maximum entropy approach to species distribution modeling. In: ICML '04. Proceedings of the twenty-first international conference on Machine learning. ACM, New York, 655-662.

Pressey RL, Hager TC, Ryan KM, Schwarz J, Wall S, Ferrier S, Creaser PM. 2000. Using abiotic data for conservation assessments over extensive regions: quantitative methods applied across New South Wales, Australia. Biological Conservation 96(1): 55-82.

Quantum GIS Development Team. 2016. Quantum GIS Geographic Information System. Open 505 Source Geospatial Foundation Project. Available at http://qgis.osgeo.org

R Core Team. 2016. R: A language and environment for statistical computing. R Foundation for 507 Statistical Computing, Vienna, Austria. Available at https://www.R-project.org/

Randall RP. 2007. The introduced flora of Australia and its weed status. Adelaide: CRC for Australian Weed Management.

Raimondo D, von Staden L, Foden W, Victor JE, Helme NA, Turner RC, Kamundi DA, Manyama PA. 2009. Red List of South African Plants. Pretoria: South African National Biodiversity Institute,

513 Ramankutty N, Foley JA. 1999. Estimating historical changes in global land cover: croplands from 1700 to 1992. Global Biogeochemical Cycles 13(4): 997-1027. 
515 Recart W, Ackerman JA, Cuevas AA. 2013. There goes the neighborhood: apparent competition

516 between invasive and native orchids mediated by a specialist florivorous weevil. Biological

$517 \quad$ Invasions 15: 283-293.

518 Rewicz A, Kołodziejek J, Jakubska-Busse A. 2015. The role of anthropogenic habitats as substitutes for natural habitats: a case study on Epipactis helleborine (L.) Crantz (Orchidaceae, Neottieae). Variations in size and nutrient composition of seeds. Turkish Journal of Botany 40: 258-268.

522 Russell C. 2015. New and emerging weeds on site. Naturelink 22(1): 11.

523 Scott JK, Delfosse ES. 1992. Southern African plants naturalised in Australia: a review of weed status and biological control potential. Plant Protection Quarterly 7: 70-80.

525 Scott JK, Panetta FD. 1993. Predicting the Australian Weed Status of Southern African Plants. 526 Journal of Biogeography 20(1): 87.

527 Sinden J, Jones R, Hester S, Odom D, Kalisch C, James R, Cacho O. 2004. The economic impact 528 of weeds in Australia, Technical Series no. 8. Australia: CRC for Australian Weed Management.

530 Soberón J, Villalobos F. 2011. The crucial role of the accessible area in ecological niche modeling and species distribution modeling. Ecological Modelling 222: 1810-1819.

532 Sol D. 2001. Predicting invaders. Trends in Ecology \& Evolution 16: 544.

533 Suárez-Seoane S, García de la Morena EL, Morales Prieto MB, Osborne PE, de Juana E. 2008. Maximum entropy niche-based modelling of seasonal changes in little bustard (Tetrax tetrax) distribution. Ecological Modelling 219: 17-29. 
536 Thiers B. 2018. Index Herbariorum: A global directory of public herbaria and associated staff.

537 New York Botanical Garden's Virtual Herbarium. Available at

538 http://sweetgum.nybg.org/ih/

539 Thorp J, Lynch R. 2000. The Determination of Weeds of National Significance. Launceston:

$540 \quad$ Natural Heritage Trust/National Weeds Strategy Executive Committee..

541 Thuiller W, Alberta C, Araújo MB, Berry PM, Cabeza M, Guisan A, Hickler T, Midgley GF, Paterson J, Schurr FM, Sykes MT, Zimmermann NE. 2008. Predicting global change impacts on plant species' distributions: future challenges. Perspectives in Plant Ecology, Evolution and Systematics 9(3-4): 137-152.

545 Torchin ME, Lafferty KD, Dobson AP, McKenzie VJ, Kuris AM. 2003. Introduced species and their missing parasites. Nature 421(6923): 628-630.

547 Tucker P. 2006 Monadenia - a trial. Trees For Life. Available at https://www.treesforlife.org.au/sites/default/files/Monadenia\%20-\%20A\%20Trial.PDF

Wang C-J, Wan J-Z, Qu H, Zhang Z-X. 2017. Modelling plant invasion pathways in protected areas under climate change: implication for invasion management. Web Ecology 17: 6977. https://doi.org/10.5194/we-17-69-2017

552 Warren DL, Glor RE, Turelli M. 2008. Environmental niche equivalency versus conservatism: quantitative approaches to niche evolution. Evolution 62: 2868-2883.

554 Warren DL. 2016. ENMTools: Analysis of niche evolution using niche and distribution models. $555 \quad$ R package version 0.1 .

556 Wileman R. 2015. Disa bracteata. The South African weed orchid. Correa Mail 312: 4-5.

557 Walas L, Dering M, Ganatsas P, Pietras M, Pers-Kamczyc E, Iszkuło G. 2018. The present status 558 and potential distribution of relict populations of Aesculus hippocastanum L. in Greece and 

1048-1058.

561

\section{Figures}

563 Fig. 1. The potential area of the suitable niche for Disa bracteata in Southern Africa. The insets

564 visualize: A) Potential niche modelled using current climate and soil variables, B) Potential niche modelled using current climate variables, C) Potential niche modelled using rcp26 climate change scenario, D) Potential niche modelled using rcp45 climate change scenario, E) Potential niche modelled using rcp60 climate change scenario, F) Potential niche modelled using rcp85 climate change scenario. Blue indicates not suitable and red highly suitable. Green dots denote accessions used in ecological niche modeling. Lines show major rivers within the region. Maps were drawn using WGS 1984 (EPSG:4326) coordinate system.

Fig. 2. The potential area of the suitable niche for Disa bracteata in Australia and adjacent islands.

572 The insets visualize: A) Potential niche modelled using current climate and soil variables, B)

573 Potential niche modelled using current climate variables, C) Potential niche modelled using rep26

574 climate change scenario, D) Potential niche modelled using rcp45 climate change scenario, E)

575 Potential niche modelled using rcp60 climate change scenario, F) Potential niche modelled using 576 rcp85 climate change scenario. Blue indicates not suitable and red highly suitable. Purple dots 577 denote accessions used in ecological niche modeling. Lines show administrative borders. Maps 578 were drawn using WGS 1984 (EPSG:4326) coordinate system.

579 Fig. 3. Environmental niche of Disa bracteata as visualized by principal component analysis 580 (PCA). Diagram was constructed with environmental values recorded for natural and invasive 581 populations. Blue background indicates the whole environment included in the analysis present in 
582 Africa and Australia. Native and invasive populations are enclosed by circles encompassing 95\%

583 of the data. While native populations occupy a slightly broader niche some of the invasive

584 populations occupy habitats not present in its native niche.

585 Fig. 4. Boxplot diagram of the environmental values recorded in the areas of occurrence of natural 586 and invasive populations of Disa bracteata. In addition to examining invasive populations as a 587 whole they are divided into Western Australia (W-AUS) and Eastern Australia (E-AUS). Bio15 588 Precipitation Seasonality $(\mathrm{CoV})$, bio18 - Precipitation in the Warmest Quarter [mm], bio19 589 Precipitation in the Coldest Quarter [mm], bio7 - Temperature Annual Range $\left[{ }^{\circ} \mathrm{C}\right]$, bio 8 - Mean

590 Temperature in the Wettest Quarter $\left[{ }^{\circ} \mathrm{C}\right]$, soil.organic.carbon content is expressed in [g per $\left.\mathrm{kg}\right]$,

591 Soil.pH refers to a $\mathrm{pH} \times 10$ in $\mathrm{H}_{2} \mathrm{O}$, Sand.content is expressed as a mass fraction in percent. Areas

592 are compared to each other using T-tests. Circles are means, horizontal lines minimum and 593 maximum values, the box represents first and third quantiles, and vertical line inside delineates the 594 median.

595 Fig. 5 Histogram of climates recorded in the known populations divided into: natural (South 596 African), invasive (Australian), E-AUS (Eastern Australian), and W-AUS (Western Australian).

597 Two types of climate present in Africa are not occupied in Australia. Invasive populations occur 598 mainly within Csb climate with $\mathrm{Cfb}$ as the second most frequent in the Eastern Part and Csa as the 599 second one in the Western Part of Australia. Shortcuts follow standard Köppen-Geiger climate 600 classification system: BSh - Hot Semi-Arid, BSk - Cold Semi-Arid, Cfa - Humid Subtropical, Cfb 601 - Marine - Mild Winter, Csa - Interior Mediterranean, Csb - Coastal Mediterranean. Prior to the 602 analysis occurrences were rarified to match resolution of climate map $\left(10 \mathrm{~km}^{2}\right)$.

603 Supplementary file 1. List of localities used in the ecological niche modeling. 
604 Supplementary file 2. Initial variables used by MaxentVariableSelection to choose appropriate 605 set of variables and betamultiplier. Topographic variables marked with "Calculated"” as a source 606 were calculated with "raster" package in R using function "terrain" on altitude dataset. Variables 607 used for modeling are marked with bold. All variables were used for PCA.

608 Supplementary file 3. PCA diagram displaying environmental values recorded for the 609 populations studied. Points are coloured according to the decade in which they were recorded. 610 Groups for a particular decade have different colour assignments and are enclosed in a circle 611 encompassing $95 \%$ of the data. There is a visible shift in invasive populations, which move 612 towards negative axis values.

613 


\section{Table $\mathbf{1}$ (on next page)}

Results of bias metric.

If invasive populations would occupy the same habitat as natural the result will be 0 . Negative values indicate occupation of sites below median found in the natural range, whereas positive values indicate occupation of sites above the median. The greater the number is (or lower in case of negative values) the greater is the difference. 


\begin{tabular}{|c|c|c|c|c|c|c|c|c|}
\hline & bio07 & bio08 & bio15 & bio18 & bio19 & Sand content & $\begin{array}{l}\text { Soil Organic } \\
\text { Carbon } \\
\text { Content }\end{array}$ & Soil pH \\
\hline Australia & 24.9 & -23.6 & -6.0 & -10.5 & -7.1 & 47.6 & 14.7 & -14.3 \\
\hline $\begin{array}{l}\text { Eastern } \\
\text { Australia }\end{array}$ & 27.9 & -24.9 & -8.8 & -10.3 & -8.0 & 47.6 & 16.0 & -14.3 \\
\hline $\begin{array}{l}\text { Western } \\
\text { Australia }\end{array}$ & 6.2 & -4.0 & 11.9 & -12.9 & 10.5 & 52.4 & -2.0 & -4.8 \\
\hline
\end{tabular}

2 Table 1 - Results of bias metric. If invasive populations would occupy the same habitat as

3 natural the result will be 0 . Negative values indicate occupation of sites below median

4 found in the natural range, whereas positive values indicate occupation of sites above the

5 median. The greater the number is (or lower in case of negative values) the greater is the

6 difference. 


\section{Figure 1}

The potential area of the suitable niche for Disa bracteata in Southern Africa.

The insets visualize: (A) Potential niche modelled using current climate and soil variables, (B) Potential niche modelled using current climate variables, (C) Potential niche modelled using rcp26 climate change scenario, (D) Potential niche modelled using rcp45 climate change scenario, (E) Potential niche modelled using rcp60 climate change scenario, (F) Potential niche modelled using rcp85 climate change scenario. Blue indicates not suitable and red highly suitable. Green dots denote accessions used in ecological niche modeling. Lines show major rivers within the region. Maps were drawn using WGS 1984 (EPSG:4326) coordinate system. 


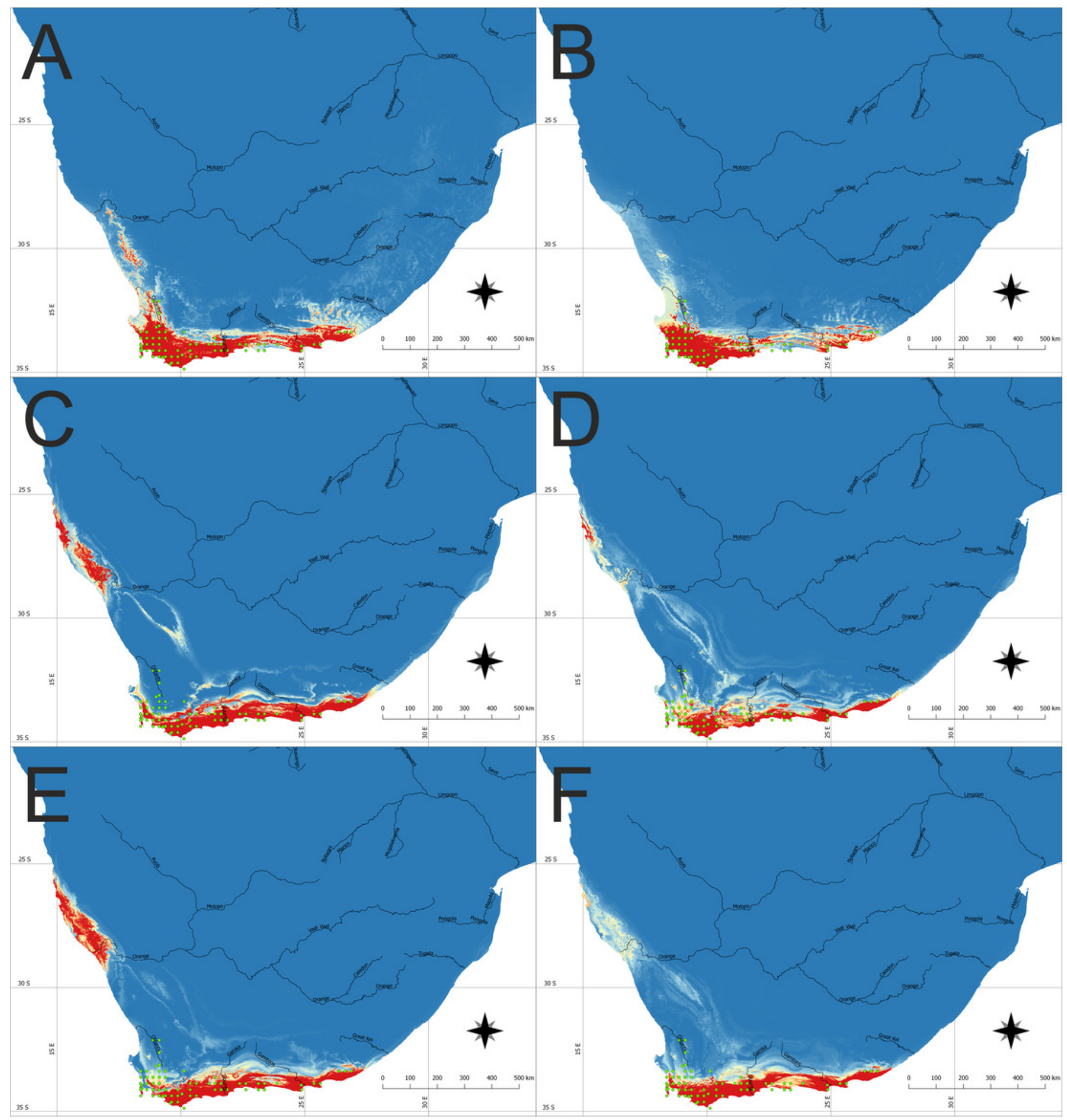




\section{Figure 2}

The potential area of the suitable niche for Disa bracteata in Australia and adjacent islands.

The insets visualize: (A) Potential niche modelled using current climate and soil variables, (B) Potential niche modelled using current climate variables, (C) Potential niche modelled using rcp26 climate change scenario, (D) Potential niche modelled using rcp45 climate change scenario, (E) Potential niche modelled using rcp60 climate change scenario, (F) Potential niche modelled using rcp85 climate change scenario. Blue indicates not suitable and red highly suitable. Purple dots denote accessions used in ecological niche modeling. Lines show administrative borders. Maps were drawn using WGS 1984 (EPSG:4326) coordinate system. 


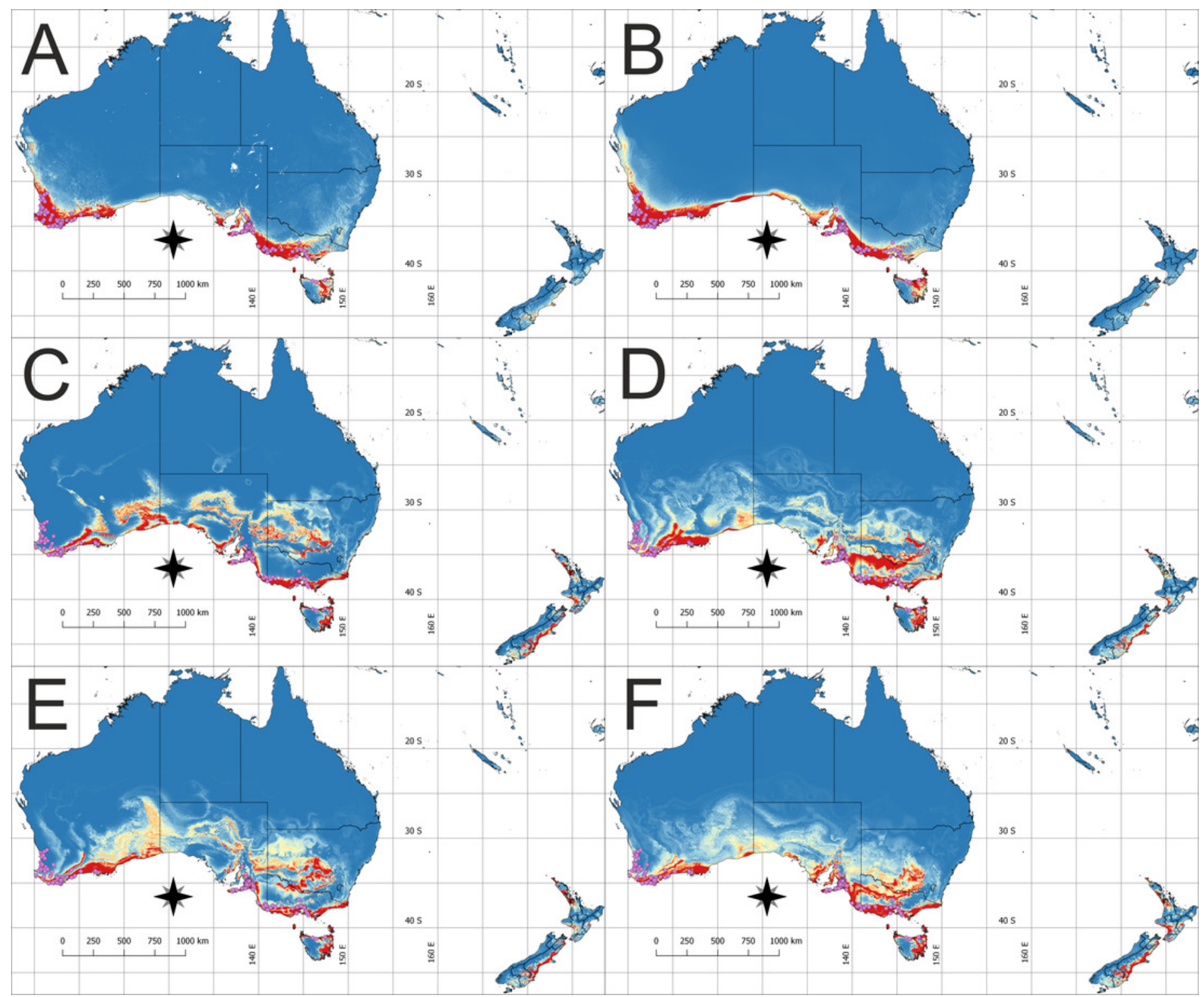




\section{Figure 3}

Environmental niche of Disa bracteata as visualized by principal component analysis (PCA).

Diagram was constructed with environmental values recorded for natural and invasive populations. Blue background indicates the whole environment included in the analysis present in Africa and Australia. Native and invasive populations are enclosed by circles encompassing $95 \%$ of the data. While native populations occupy a slightly broader niche some of the invasive populations occupy habitats not present in its native niche. 


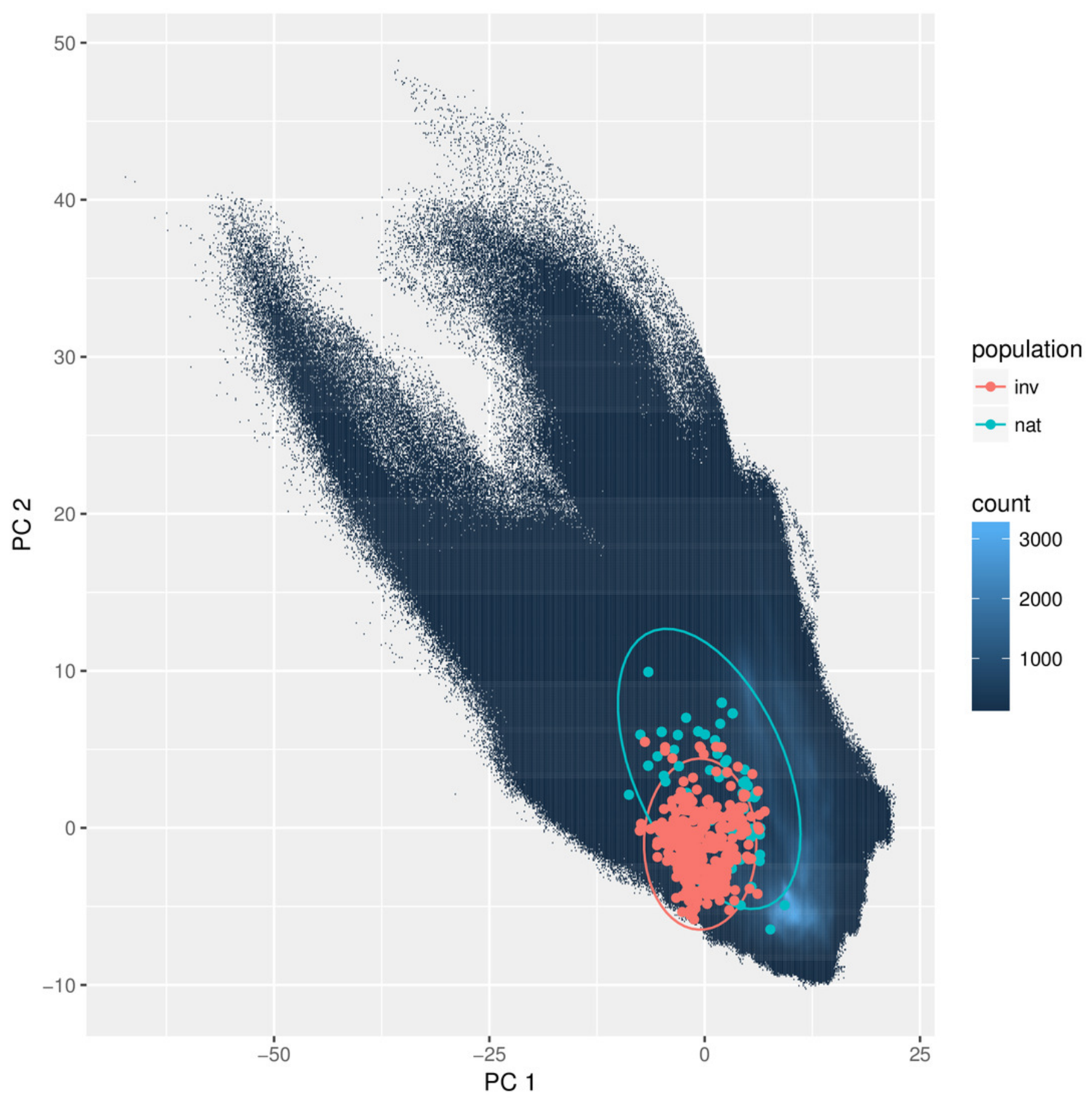




\section{Figure 4}

Boxplot diagram of the environmental values recorded in the areas of occurrence of natural and invasive populations of Disa bracteata.

In addition to examining invasive populations as a whole they are divided into Western Australia (W-AUS) and Eastern Australia (E-AUS). Bio15 - Precipitation Seasonality (CoV), bio18 - Precipitation in the Warmest Quarter [mm], bio19 - Precipitation in the Coldest Quarter [mm], bio7 - Temperature Annual Range $\left[{ }^{\circ} \mathrm{C}\right]$, bio8 - Mean Temperature in the Wettest Quarter [ ${ }^{\circ} \mathrm{C}$ ], soil.organic.carbon content is expressed in [g per kg], Soil.pH refers to a pH $\times 10$ in $\mathrm{H}_{2} \mathrm{O}$, Sand.content is expressed as a mass fraction in percent. Areas are compared to each other using T-tests. Circles are means, horizontal lines minimum and maximum values, the box represents first and third quantiles, and vertical line inside delineates the median. 


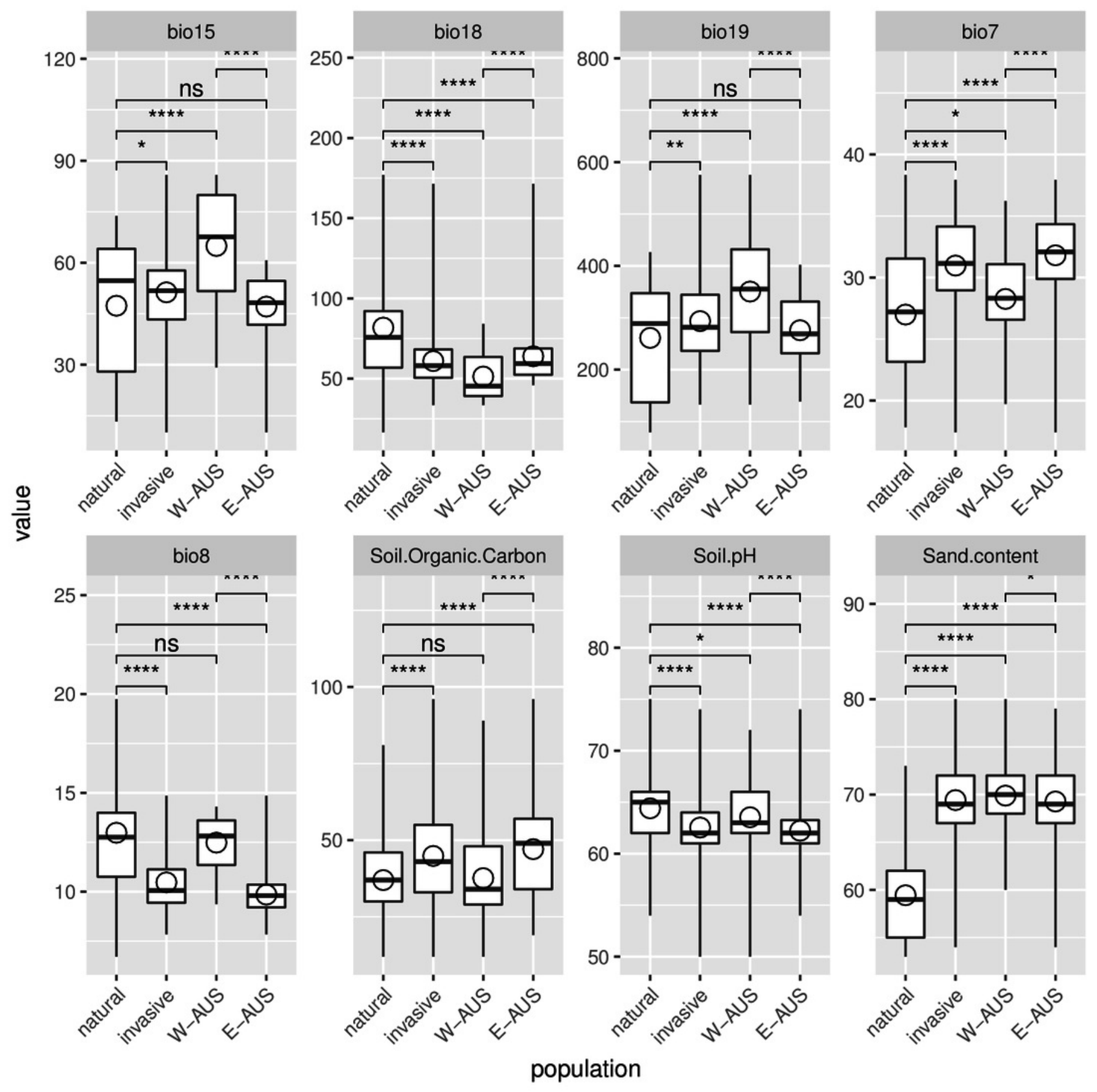




\section{Figure 5}

Histogram of climates recorded in the known populations divided into: natural (South African), invasive (Australian), E-AUS (Eastern Australian), and W-AUS (Western Australian).

Two types of climate present in Africa are not occupied in Australia. Invasive populations occur mainly within Csb climate with Cfb as the second most frequent in the Eastern Part and Csa as the second one in the Western Part of Australia. Shortcuts follow standard Köppen-Geiger climate classification system: BSh - Hot Semi-Arid, BSk - Cold Semi-Arid, Cfa Humid Subtropical, Cfb - Marine with Mild Winter, Csa - Interior Mediterranean, Csb - Coastal Mediterranean. Prior to the analysis occurrences were rarified to match resolution of climate $\operatorname{map}\left(10 \mathrm{~km}^{2}\right)$. 


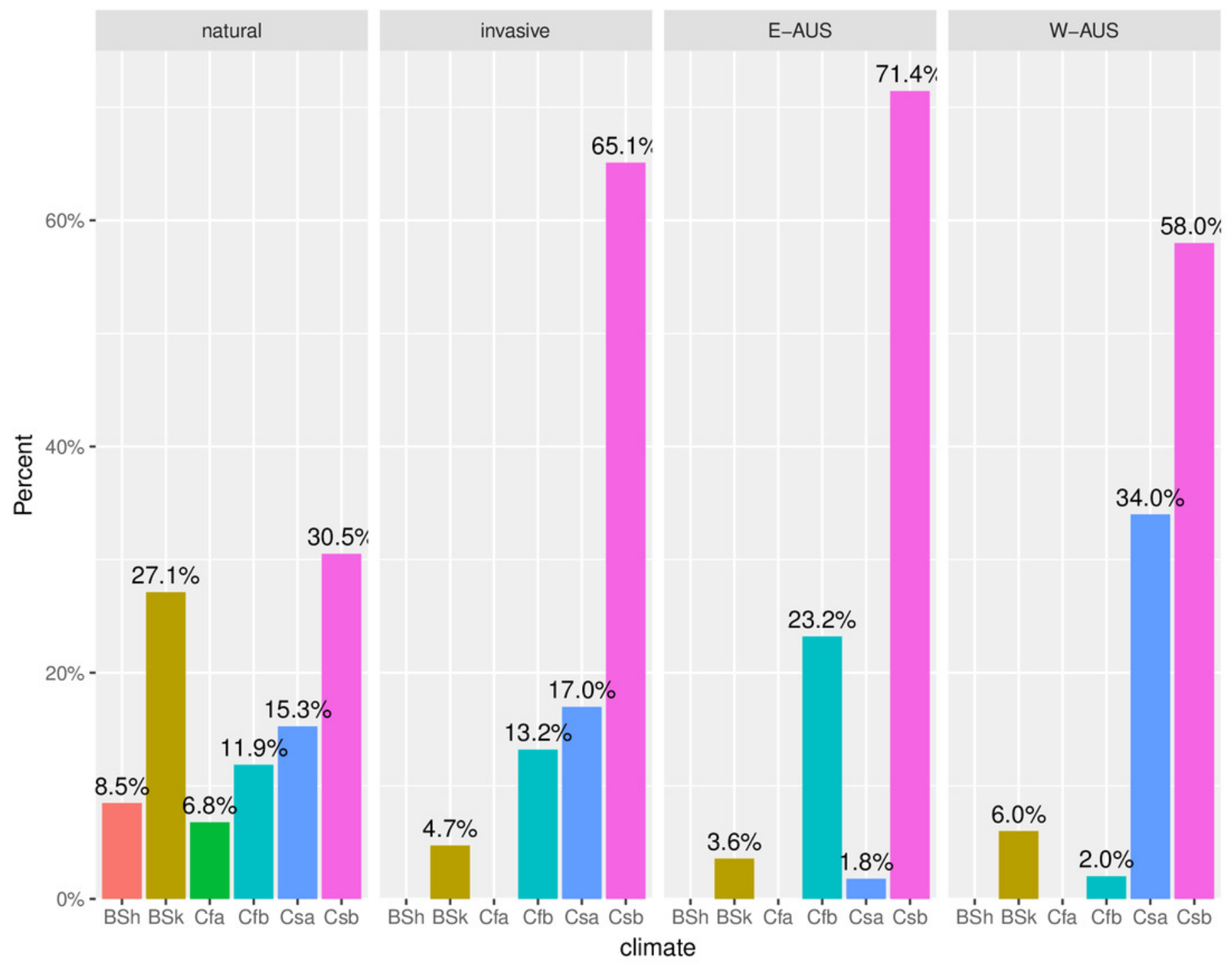

